\title{
Н.П. Дворцова
}

\section{«ВАРБЕК» БАКЮЛАРА Д'АРНО В КНИЖНОМ НАСЛЕДИИ ПАНКРАТИЯ СУМАРОКОВА}

\begin{abstract}
Аннотация. Рассматривается книжный памятник ХVIII в. - повесть Бакюлара д’Арно «Варбек», переведенная П.П. Сумароковым в Сибири и напечатанная в 1793 г. в Тамбове, в вольной типографии А.М. Нилова. Впервые реконструируются тобольско-тамбовские книгоиздательские связи, позволяющие по-новому увидеть начальный период сибирского книгопечатания от Филофея Лешинского до типографии Корнильевьх. Анализ «Варбека» в контексте «Училища любви», а также переводческой, редакторской, издательской деятельности П.П. Сумарокова периода его сибирской ссылки (1787-1801) позволяет оченить его вклад в формирование отечественной традиции назидательного чтения, сочетающего пользу и удовольствие и имеющего ичелью просвещение и воспитание чувств. Материалом для исследования послужили издание «Варбек», хранящееся в Музее книги Российской государственной библиотеки, а также тобольские книги и журналь из фондов Библиотеки Академии наук (Санкт-Петербург).
\end{abstract}

Ключевые слова: П.П. Сумароков, Бакюлар д’Apно (François-Thomas-Marie de Baculard d'Arnaud), «Варбек», вольная типография А.М. Нилова, сибирское книгопечатание, назидательное чтение.

В 2018 г. исполняется 225 лет со дня выхода в свет одной из редких и вместе с тем характерных для отечественного издательского дела XVIII в. книг - повести «Варбек», напечатанной в Тамбове, в вольной типографии А.М. Нилова, в 1793 г. «с указного дозволения». На титульном листе издания сказано также: «Варбек, англинская повесть, основанная на исторической истине, переведена с французского из сочинений г. Арнода в Сибири».

«Варбек»- наименее известная и изученная книга в творческом наследии П.П. Сумарокова, писателя, переводчика, редактора. «Англинской повести» «Училище любви», являющейся переводом книги немецкого писателя И.Г.Б. Пфейля «Торжество добродетельной любви» («Triumph der tugendhafte Liebe»), как свидетельствует библиографический путеводитель [1. С. 133-147], повезло в 
этом смысле гораздо больше - прежде всего потому, что повести этой суждено было стать первой в Сибири печатной литературнохудожественной книгой. «Варбек» же, «англинская повесть» французского писателя, переведенная П.П. Сумароковым в Сибири и напечатанная в Тамбове, до сих пор является книговедческой и филологической загадкой.

Причины исследовательского невнимания к «Варбеку» кроются, очевидно, не столько в переводном характере книги, сколько в том факте, что книга из Сибири напечатана в Тамбове. Закономерно, что о ней ничего не говорится в первом томе «Очерков книжной культуры Сибири и Дальнего Востока» в связи с судьбой П.П. Сумарокова и тобольской типографии Корнильевых [2. С. 2333], а в репертуаре вольной типографии А.М. Нилова она смотрится с точки зрения географии авторов и переводчиков достаточно чужеродно. Вместе с тем «Варбек» - очевидное свидетельство тобольско-тамбовских книгоиздательских связей, возникших благодаря переводческой и издательской деятельности П.П. Сумарокова, и в этом качестве нуждается в осмыслении и интерпретации, что и является предметом исследования в этой статье.

История «Варбека», с нашей точки зрения, помогает по-новому понять не только особенности начального этапа сибирского книгопечатания, но и личность и творчество П.П. Сумарокова. Обусловлено это прежде всего кругом вопросов, которые актуализирует история «Варбека»: как книга из Сибири могла быть напечатана в Тамбове; каково место Бакюлара д’Арно и П.П. Сумарокова в переводной литературе этого периода; как связаны между собой два переводных романа: «Училище любви» и «Варбек»?

С нашей точки зрения, публикация «Варбека» в Тамбове - событие, значимое для понимания особенностей сибирского книгопечатания, начало которого, как известно, связано с выходом в свет в 1789 г. в Тобольске, в типографии Корнильевых, «Иртыша, превращающегося в Ипокрену».

Значительно раньше попытку начать книгопечатание в Сибири предпринял митрополит сибирский и тобольский Филофей, когда в 1702 г. обратился к Петру I с челобитной по поводу «великого 
нестроения» в духовном просвещении Сибири. В челобитной он, в частности, просил «для детского учения завесть друкарню (типографию) в Тобольске, в Софийском дому, Великого Государя казною, а друковать (печатать) Буквари, Часословы малые и Псалтыри» [3. С. 14]. В указе Петра митрополиту Филофею было сказано: «...а друкарне (типографии) в Тобольске, по именному Великого Государя Указу, не быть, и какие книги понадобятся, и ему велеть покупать на Москве» [3. С. 16].

Указ этот не только задержал почти на век развитие печатного дела в Сибири, но и обозначил колониальный по сути подход государя к книжному делу Сибири. В этом контексте история публикации «Варбека» в Тамбове в 1793 г. может быть интерпретирована как проявление качественно иного подхода к печатной книге Сибири, понимаемой как органическая часть общероссийского печатного дела, в котором возможно не только движение книг из европейской части России в Сибирь, но и из Сибири в европейскую часть России.

О таком подходе свидетельствует не только история с «Варбеком», но и характер распространения первых тобольских журналов. Так, А.И. Дмитриев-Мамонов отмечает, что в 1789-1790 гг. у «Иртыша» были годовые подписчики в Тобольском (13 городов), Колыванском (2 города), Пермском (9 городов), Вятском (9 городов), Ярославском (1 город) наместничествах [4. С. 3637]. Журнал «Библиотека ученая, экономическая, нравоучительная, историческая и увеселительная в пользу и удовольствие всякого звания читателей» в 1793-1794 гг. рассылался 112 подписчикам в Москву, Санкт-Петербург, а также в 19 наместничеств, в ряду которых - Иркутское, Нижегородское, Смоленское, Орловское, Харьковское, Рязанское, Тверское, Симбирское, Киевское, Черниговское, Воронежское, а также Тамбовское и др. [Там же. C. 75-76]. Дмитриев-Мамонов отмечает также, что объявление о выходе в свет нового журнала «Библиотека ученая» было напечатано его редактором П.П. Сумароковым в 1792 г. в «Московских ведомостях» и «Санкт-Петербургских ведомостях» [Там же. С.77-78], что также свидетельствует о широкой известности 
«Варбек» Бакюлара д’Арно в книжном наследии Панкратия Сумарокова 21

журнала, осознававшегося его создателями не как узкосибирское, а как общероссийское явление.

В этом контексте важен также тот факт, что во время ссылки в Сибирь (1787-1801), особенно ближе к концу ее, П.П. Сумароков активно печатался в Москве, в Университетской типографии у Х. Ридигера и Х. Клаудиа. Здесь были опубликованы «Аониды» (1798-1799); первый поэтический сборник ссыльного поэта «Собрание некоторых сочинений, подражаний и переводов» (1799); «Совершенный лакировщик, или Полное и подробное руководство к составлению и употреблению всякого рода лаков, как спиртовых, так скипидарных и масляных, содержащих в себе более ста лучших рецептов оным; с приобщением всех особливейших, новейших и малоизвестных секретов, касающихся до сего приятного художества» (1799); «Источник здравия, или Словарь всех употребительных снедей, приправ и напитков, из трех царств природы извлекаемых, с подробным описанием их лекарственных сил или вредных действий в теле человеческом, смотря по различным темпераментам или сложениям оного, с присовокуплением многих полезнейших и новейших открытий, касательно сохранения здоровья и врачевания болезней как внутренних, так и наружных. Извлек из новейших медико-физических сочинений и в пользу пекущихся о здравии своем особ издал Панкратий Сумароков» (1800).

Тот факт, что для П.П. Сумарокова сибирская книга существует в едином российском издательском пространстве, позволяет понять возможность публикации «Варбека» в Тамбове, но не объясняет само это событие. Объяснить его можно, очевидно, ответив на два взаимосвязанных вопроса: «Почему “Варбек” не был напечатан в Тобольске?»; «Почему и как произведение Бакюлара д’Арно было напечатано в Тамбове?».

Ответ на оба эти вопроса предложил в «Повести о Панкратии Сумарокове» известный историк уральского и сибирского книжного дела В.А. Павлов, что представляется закономерным, ибо, с нашей точки зрения, история «Варбека» связана прежде всего с П.П. Сумароковым, сумевшим соединить в своей судьбе две вольные типографии - тобольскую и тамбовскую. 
В.А. Павлов попытался ответить на вопрос, почему перевод «Варбека» появился не в Тобольске? В ситуации отсутствия документальных свидетельств его догадки, как он полагал, выглядят вполне убедительно. На вопрос этот у В.А. Павлова есть три ответа, каждый из которых следует начать со слова «возможно»: 1) «между Сумароковым и Корнильевым “пробежала черная кошка"»; 2) «типография была настолько перегружена заказами наместнического правления, что Корнильев не чаял справиться с новым заказом»; 3) «тобольская управа благочиния не разрешила печатать “Варбека" по причине того, что "главное действующее лицо сочинения - самозванец, добивавшийся трона”, а в памяти тоболяков и, в частности, епископа Варлаама еще свежи были воспоминания об отечественном самозванце Емельяне Пугачеве, выступавшем под личиной императора Петра III» [5].

Предположение В.А. Павлова о черной кошке, пробежавшей между П.П. Сумароковым и В.Я. Корнильевым, может быть оспорено тем фактом, что в 1793-1794 гг. в тобольской типографии печатался журнал П.П. Сумарокова «Библиотека ученая» (12 выпусков), который рассылался, как уже было сказано, едва ли не по всей России. Епископа Варлаама в 1793 г. трудно заподозрить в страхе перед Емельяном Пугачевым, казненным в 1775 г., тем более что в 1787 г. в Собрании сочинений А.П. Сумарокова, изданном Н.И. Новиковым, была напечатана его знаменитая трагедия «Димитрий Самозванец». Сам факт публикации трагедии, впервые поставленной на Императорской сцене в Санкт-Петербурге в 1771 г., делал тему самозванства официально включенной в культурный контекст времени.

В.А. Павлов предпринимает попытку, вполне, с нашей точки зрения, убедительную, объяснить, как «Варбек» оказался в Тамбове. На основе изданного А.М. Ниловым в 1793 г. «Реестра российским книгам, продающимся в вольной тамбовской типографии» он делает вывод, что посредником между П.П. Сумароковым и А.М. Ниловым, скорее всего, был двоюродный дядя П.П. Сумарокова - Павел Иванович Сумароков, в 1791 г. опубликовавший в Тамбове в своем переводе книгу С.Ф. Жанлис «Аделия и Теодор, 
«Варбек» Бакюлара д’Арно в книжном наследии Панкратия Сумарокова 23

или Письма о воспитании, содержащие в себе правила, касающиеся до трех различных способов воспитания, как то принцов и обоего пола юношества». В.А. Павлов не без основания утверждает: «Павел Иванович близко к сердцу принимал нужды несчастного родственника. Вероятно, он-то и посоветовал отправить рукопись "Варбека" в Тамбов... Следуя за дядей, Панкратий Платонович, вероятно, продал Нилову рукопись перевода, а вместе с нею и право издания повести» [5]. Следует отметить также, что в 1801 г., после воцарения императора Александра I, П.И. Сумароков, будучи в должности сенатора, помогает ссыльному поэту вернуться из Сибири [1. С. 54].

Анализ репертуара тамбовской типографии позволяет сделать еще одно, менее убедительное, предположение о посреднике между П.П. Сумароковым и А.М. Ниловым. «Сводный каталог русской книги гражданской печати XVIII века. 1725-1800» свидетельствует о том, что с 1792 по 1795 г. в тамбовской типографии было издано 4 книги, переведенных «в селе Богородицком, новое Мансырово тож» вахмистром лейб-гвардии конного полка Павлом Никифоровым (1792, 1793), девицею Надеждою Никифоровой (1794) и «от армии капитаном» Стефаном Никифоровым (1795). В связи с тем, что П.П. Сумароков был отправлен в Сибирь в 1787 г. как корнет лейб-гвардии конного полка, можно предположить, что он был знаком с вахмистром, который (семья которого) и стал посредником между ним и А.М. Ниловым. К сожалению, документальное подтверждение этой гипотезы в настоящее время отсутствует.

В судьбе и репертуаре вольных типографий в Тамбове (17881796) и Тобольске (1789-1805) много общего. Прежде всего, история их почти целиком укладывается в период между двумя указами Екатерины II: об открытии вольных типографий в 1783 г. и их закрытии в 1796 г. Деятельность типографий связана с открытием и в Тамбове и в Тобольске Главных народных училищ, т.е. с политикой Екатерины II, направленной на распространение в России просвещения. Закономерно, что в тамбовской вольной типографии в 1788 г. издается объемом 16 страниц «Речь, говоренная в 22 день сентября 1786 г. при открытии в Тамбове главного народного учи- 
лища, Козловской округи села Никольского что на Сурене, однодворцем Петром Михайловым сыном Захарьиным и в том же году переведена в Санкт-Петербурге на разные иностранные языки». В 1788 г. в Тамбове была, кроме того, издана книга объемом 10 страниц под названием «Торжество восшествия на престол ее императорского величества Екатерины Второй, отправленное в Тамбове 1786 года июня 28 дня» [6. С. 282].

В Предисловии к первому (сентябрьскому) номеру «Иртыша, превращающегося в Ипокрену» за 1789 г. говорится, в частности: «Тобольское главное народное училище предприняло издавать ежемесячник, наполняя оный всякого рода как сочинениями, так и переводами в стихах и прозе». Открывает номер «Речь, говоренная при открытии тобольского главного народного училища учителем высших классов Иваном Лафиновым 1789 года марта 11 дня», в которой о Екатерине Великой сказано: «Всепресветлейшая монархиня, чадолюбивая матерь наша, с тем учреждает училище, дабы всякий юноша мог быть истинный и полезный сын отечества». Училище же названо местом, которое «может питать души достойными человека плодами просвещения» [7. С. 1]. В «Оде Иртышу, превращающемуся в Ипокрену» (январь 1790 г.) Иван Трунин продолжит тему:

Счастливой зря свою судьбину,

Прославь, Сибирь, Екатерину,

Благую матерь чад своих [8. С. 39].

Есть еще одна особенность, сближающая деятельность вольных типографий в Тобольске и Тамбове: она была бы невозможна без участия в ней поэтов - Г.Р. Державина в Тамбове, П.П. Сумарокова в Тобольске. Обе типографии появляются в результате самого тесного союза просвещения и поэзии. Возникновение вольной типографии в Тамбове связано, как известно с деятельностью Г.Р. Державина на посту тамбовского губернатора (1786-1788), открыта она была при посредничестве Н.И. Новикова, а после отъезда Г.Р. Державина из Тамбова типографию возглавил А.М. Нилов, который был хорошо знаком с поэтом-губернатором, полу- 
«Варбек» Бакюлара д’Арно в книжном наследии Панкратия Сумарокова 25

чившим, кстати, в 1792 г. в дар от А.В. Алябьева, правителя Тобольского наместничества, восемь экземпляров «Иртыша, превращающегося в Ипокрену» за 1791 г. [4. С. 40, 43]. Если история типографии Корнильевых начинается с издания журнала «Иртыш, превращающийся в Ипокрену», то деятельность типографии А.М. Нилова - с издания 1 января 1788 г. газеты «Тамбовские известия». Журналов не издавали в Тамбове, газет - в Тобольске, но работа каждой из типографий начинается с печатания периодического издания.

Репертуар типографий также можно назвать предельно близким и в целом характерным для издательского дела в России конца XVIII в. [2. С. 33], с очевидной тем не менее спецификой репертуара в каждой из них. Прежде всего, в обеих типографиях доминируют книги, говоря современным языком, гуманитарной направленности, отличающиеся тематическим разнообразием. Так, в ряду тобольских книг (11 наименований) есть книги художественные, исторические, юридические, богословские, медицинские, ветеринарные и др. [9. С. 239-240]. Из них 4 (36\%) переводные. Доминируют же в Тобольске книги, которые сегодня называются документальными (non fiction). По нашим подсчетам, из 19 наименований тамбовских книг 14 (74\%) являются переводными, среди них литературно-художественные, философские, исторические, педагогические и др. [10. С. 290].

Книжный репертуар тамбовской типографии, таким образом, отличается большим количеством переводных изданий и бо́льшим книжным разнообразием. В 1788 г. здесь, например, опубликовано либретто оперы Е.И. Фомина «Ямщики на подставе. Игрище невзначай» [11. С. 186].

Отличие и разнообразие репертуара тобольской и тамбовской типографий не отменяет общих типологических закономерностей, в частности роли переводных книг в их репертуаре. С этой точки зрения «Варбек» Б. д’Арно в переводе П.П. Сумарокова органично вписывается в структуру репертуара и в Тамбове, и в Тобольске.

Переводная книга и переводная литература, как известно, важнейшая особенность отечественной культуры XVIII в. Так, авторы 
фундаментальной «Истории русской переводной художественной литературы» убедительно доказывают: «Переводная литература до самого конца века оказывается неотъемлемой частью отечественной словесности и языковой культуры [12. С. 228]. Тем не менее, с их точки зрения, «многие русские переводчики в России XVIII в. литературным трудом не могли обеспечить свое существование» [12. С. 151]. Возможно, этим объясняется разнообразие переводчиков в вольной тамбовской типографии: книги переводят княгиня Варвара Голицина (1790), «девица Надежда Никифорова в селе Богородском» (1794), «девица Марья Орлова в селе Покровском» (1788), ссыльный поэт П.П. Сумароков, капитан Стефан Никифоров (1795), вахмистр Павел Никифоров (1792) и т.д.

Среди переводчиков, кроме того, распространены семейнородственные связи. Так, в Тамбове книги переводят Андрей Нилов (1790), Корнилий Нилов (1793) и Е.К. Нилова (1793-1796), а в Тобольске - П.П. Сумароков и С.А. Сумарокова. Возможно, именно такой характер переводчиков объясняет тот факт, что «сравнительно большое место в этом потоке переводной художественной литературы, который устремился в Россию во второй половине XVIII века, занимают произведения, не оставившие скольконибудь заметного следа у себя на родине» [Там же. С. 155].

В историю русской переводной художественной литературы XVIII в. Франсуа Тома Мари де Бакюлар д’Арно (1718-1805) вошел как писатель, приобретший в России особую популярность в контексте концепции так называемого назидательного чтения, т.е. сочетания в романе приятного с полезным [Там же. С. 145-146]. С нашей точки зрения, именно в русле этой концепции - для пользы и удовольствия всякого звания читателей - издавал журнал «Библиотека ученая», а также свои книги П.П. Сумароков.

По данным «Сводного каталога русской книги гражданской печати XVIII века. 1725-1800», в России в XVIII в. было издано 30 книг Арно, включая два объемных тома в Университетской типографии у Н.И. Новикова под названием «Успокоение чувствительного человека, или Собрание сочинений г. Арнода, прославившегося писанием трогающих и удовольствие приносящих по- 
«Варбек» Бакюлара д’Арно в книжном наследии Панкратия Сумарокова 27

вестей в англинском вкусе. С присовокуплением гравированных изображений к каждой повести» (1789) [6. С. 56-59]. Нельзя не отметить и тот факт, что первый перевод Арно в России в 1769 г. был сделан Д.И. Фонвизиным.

Востребованность Арно у издателей и читателей объясняется, очевидно, тем, что он «написал множество небольших по объему романов и повестей с мелодраматическими сюжетами, нагромождая в них мрачные эпизоды с роковыми тайнами, переодеваниями, похищениями, кораблекрушениями, заговорами, поединками. Герои его постоянно льют слезы радости и печали, падают в обмороки и т.п. В известной степени Арно ориентировался на английский приключенческий роман... В то же время его произведениям присущи некоторые руссоистские мотивы - мечты о слиянии с природой, уединении» [12. С. 177].

С нашей точки зрения, выбор П.П. Сумароковым «Варбека» Арно для перевода объясняется не только популярностью французского писателя в России, т.е. причинами внешними, но и причинами внутренними, связанными с опытом П.П. Сумарокова, переводчика «Училища любви», издававшего книги «в пользу и удовольствие всякого звания читателей».

Нравоучительная повесть И.Г.Б. Пфейля «Торжество добродетельной любви», попавшая в Тобольск благодаря французскому переводу-посреднику «Школа любовников» (L’ecole des amants) [13. С. 107-120], названа П.П. Сумароковым «Училище любви» не случайно. Сам автор-переводчик объясняет это властью «чувствований» над поступками, жизнью и судьбой человека. «Назвав повесть сию Училище любви, я не предпринимаю [попытку] оправдать сей, может быть, слишком неосторожный поступок Фаннин... чувствование оправдывает поступки наши в самое то время, когда оно нас заблуждает», - читаем в повести [14. С. 67].

Теме чувствований и страстей подчинены и главные вопросы произведения: «Что есть сердце человеческое?» и «Каким именем назвать мечту человеческого блаженства?» [14. С. 29]. На эти вопросы в повести даются внятные ответы: сердце человеческое существует в любви, которая достигается долгим подвигом, восхож- 
дением человека к высшей добродетели, к любви небесной. Вся жизнь человека предстает в повести как «училище любви». Закономерен с этой точки зрения финал произведения: «Постоянство торжествует над сердцем заблуждающимся! Оно возвращает его на прямой путь. Страдания его никогда не остаются без вознаграждения; и сквозь мучительных и бесконечных исканий достигает оно до истинного блаженства» [14. С. 142].

Помимо темы чувствований и страстей в «Училище любви» есть и другие топосы (общие места) сентименталистской прозы: руссоистское в основе противопоставление города и природы, сельской жизни; мотивы дружбы, самопожертвования, слез, страданий, пути, исканий и т.п. Все они характерны и для «Варбека», отличие которого от «Училища любви» обусловлено, помимо его трагической тональности, прежде всего тем, что повесть эта, как сказано в заглавии, основана на исторической истине. В «Варбеке» вследствие этого два основных сюжета - исторический, служащий прежде всего приключенческим фоном действия, и любовный, главный, с нашей точки зрения.

История жизни Перкина Варбека (Уорбека), самозванца и лженаследника короля Эдуарда IV, богата приключениями. Не случайно она привлечет внимание английской пистаельницы Мэри Шелли, создавшей в 1830 г. роман «Судьба Перкина Уорбека» («The Fortunes of Perkin Warbeck»). Историческая правда («дух заговоров и враждования» [15. С. 7]) в повести Арно, однако, отступает перед правдой художественной, точнее, подчиняется ей. Так, в финале повести «злощастная» Екатерина Гордон, графиня Гунтлей умирает почти сразу же после смерти Варбека, подтверждая мысль автора о том, что сильна, как смерть, любовь. Однако реальная Кэтрин Гордон прожила после смерти Перкина Уорбека почти сорок лет и при этом три раза выходила замуж.

Правда истории отступает в повести также перед всесильной логикой чуда и правдой народного мифологического сознания, включающего историю Варбека и графини Гунтлей в контекст истории любви и бедствий Абеляра и Элоизы. Так, в завершающей повесть сцене смерти сына Варбека и графини Гунтлей сказано: «Оста- 
«Варбек» Бакюлара д’Арно в книжном наследии Панкратия Сумарокова 29

лось на сей случай народное предание, что будто возобновилось тогда чудо, случившееся при погребении Элойзы возле Абеларда, графиня, говорят, приняла в объятия сына своего» [15. С. 298].

Варбек появляется в повести с характеристикой «честолюбив и влюблен» [Там же. С. 12]. «Он стал новое некоего рода бытие, сотворенное честолюбием и любовью», - говорится о герое в начале сюжета [Там же. С. 24], динамика которого определяется борьбой двух этих страстей в его душе. Завершение истории Варбека связано с победой любви над честолюбием и тщеславием: «Одна любовь виною всех преступлений моих и несчастий», - осознает Варбек, заявляя: «Я простой смертный, коего парящая душа, чувствительность, пожирающая любовь возносила превыше прочих человеков» [Там же. С. 230, 231].

Графиня Гунтлей предстает в повести типичной героиней сентиментальной повести, овеянной духом Ж.-Ж. Руссо: «Она почти всегда в деревне, в глубоком уединении... природа прекраснее ее ничего не сотворила» [Там же. С. 77]. В Варбеке она видит прежде всего «чувствительную душу» [Там же. С. 79]. К «чувствительным душам» [Там же. С. 61] обращена и вся история любви Варбека и графини Гунтлей.

В статье «О книжной торговле и любви к чтению в России», напечатанной в «Вестнике Европы» в 1802 г., Н.М. Карамзин, предложивший вернувшемуся из Сибири П.П. Сумарокову в конце 1803 г. сменить его на посту редактора журнала, задается вопросом: «Какого рода книги у нас более всего расходятся?» - и приходит к выводу: более всего в России на рубеже XVIII-XIX вв. читаются романы, которые с жанровой точки зрения в переводной русской литературе XVIII в. «было трудно, а порой и невозможно разграничить» с повестью [12. С. 229]. «Не мудрено, - утверждает Карамзин, - сей род сочинений, без сомнения, самый любопытнейший для большей части публики, занимая сердце и воображение... изображая сильнейшую и притом самую обыкновенную страсть в ее разнообразных действиях. Не всякий может философствовать или ставить себя на место героев истории, но всякий любит, любил или хотел любить» [16. С. 60]. 
С точки зрения Н.М. Карамзина, с которым трудно не согласиться, «романы способствуют просвещению», ибо «всякое приятное чтение имеет влияние на разум, без которого ни сердце не чувствует, ни воображение не представляет» [16. С. 62]. Анализ того, что читают его современники, Н.М. Карамзин заканчивает весьма современно звучащими словами: «Не знаю, как другие, а я радуюсь, лишь бы только читали» [Там же. С. 61].

Известно, что за последние сорок лет XVIII в. в России было выпущено 800 названий романов, что во многом связано с модой на образованность в среде русского дворянства [17. С. 178]. Два из них - «Училище любви» и «Варбек» - скромный и вполне убедительный вклад П.П. Сумарокова в дело отечественного просвещения и воспитания чувств.

Изучение судьбы и места «Варбека» Бакюлара д’Арно в книжном наследии П.П. Сумарокова позволяет по-новому, через систему тобольско-тамбовских книгоиздательских связей, увидеть особенности печатного дела в России конца XVIII в., а также поновому оценить масштаб личности писателя, переводчика, редактора П.П. Сумарокова, издававшего книги и журналы «в пользу и удовольствие всякого звания читателей».

\section{Лumepamypa}

1. Ларкович Д.В. Литературная судьба Панкратия Платоновича Сумарокова: (Опыт семантического анализа). Сургут : СурГПУ, 2007. 168 с.

2. Очерки истории книжной культуры Сибири и Дальнего Востока. Новосибирск: ГПНТБ СО РАН, 2000. Т. 1.316 с.

3. Челобитная митрополита сибирского и тобольского Филофея Лещинского Петру Великому и ответ сего государя на нее // Сулоцкий А.И. Святитель Филофей, митрополит сибирский и тобольский, просветитель сибирских инородцев. Омск, $1882.40 \mathrm{c}$.

4. Дмитриев-Мамонов А.И. Начало печати в Сибири // Русская книжная традиция в Сибири: «тобольские инкунабулы». Екатеринбург, 2014. С. 23-106.

5. Павлов В.А. Повесть о Панкратии Сумарокове // Урал. 2004. № 6. URL: http://magazines.russ.ru/ural/2004 (дата обращения: 15.02.2018).

6. Сводный каталог русской книги гражданской печати XVIII века. 17251800. М. : ГБЛ, 1962. Т. І. 436 с. 
«Варбек» Бакюлара д’Арно в книжном наследии Панкратия Сумарокова 31

7. Иртыш, превращающийся в Ипокрену. Тобольск : Тип. В. Корнильева, 1789. Сент. $61 \mathrm{c}$.

8. Иртыш, превращающийся в Ипокрену. Тобольск : Тип. В. Корнильева, 1790. Янв. 63 с.

9. Коновалова Е.Н. Книга тобольской губернии. 1790-1917: Сводный каталог местных изданий. Новосибирск : ГПНТБ СО РАН, 2006. 528 с.

10. Сводный каталог русской книги гражданской печати XVIII века. 1725 1800. М. : Книга, 1967. Т. 5. 300 с.

11. Сводный каталог русской книги гражданской печати XVIII века. 17251800. М. : ГБЛ, 1964. Т. 2. 516 с.

12. История русской переводной художественной литературы. Древняя Русь. XVIII век : в 2 т. СПб. : Дмитрий Буланин, 1995. T. 1. 316 с.

13. Рак В.Д. К 200-летию редкого сибирского издания из фондов Библиотеки Академии наук («Училище любви». Тобольск, 1791) // Русская книжная традиция в Сибири: «тобольские инкунабулы». Екатеринбург, 2014. С. 107-120.

14. Училище любви. Англинская повесть. Тобольск : Тип. В. Корнильева, 1791. $142 \mathrm{c}$.

15. Варбек: Англинская повесть. Тамбов : Тип. А. Нилова, 1793. 306 с.

16. Карамзин Н.М. О книжной торговле и любви к чтению в России // Вестник Европы. 1802. № 9. С. 57-64.

17. История книги / под. ред. А.А. Говорова, Т.Г. Куприяновой. М. : Светотон, 2001. $400 \mathrm{c}$.

\section{BACULARD D'ARNAUD'S VARBECK IN PANKRATIY SUMAROKOV'S LITERARY LEGACY}

Tekst. Kniga. Knigoizdanie - Text. Book. Publishing, 2018, 17, pp. 18-34.

DOI: $10.17223 / 23062061 / 17 / 2$

Natalia P. Dvortsova, Tyumen State University (Tyumen, Russian Federation). E-mail:kaf_idir@utmn.ru

Keywords: P.P. Sumarokov, Baculard d'Arnaud (François-Thomas-Marie de Baculard d'Arnaud), Varbeck, Nilov's free printing house, Siberian book printing, readers' edification.

The article discusses an 18th-century book - Baculard d'Arnaud's novel Varbeck as a literary artifact. The book was translated by P.P. Sumarokov during his Siberian exile and printed in 1793 in Tambov, in A.M. Nilov's free printing house. The author studied a Varbeck copy kept in the Book Museum of the Russian State Library as well as books and magazines from the collections of the Library of the Academy of Sciences (St. Petersburg).

For the first time, Varbeck is studied in the historical context of the TobolskTambov publishing contacts which appeared owing to Sumarokov's translation (Uchilishche lyubvi [The School of Love]) and editing (Irtysh, prevrashchayushchiysya $v$ Ipokrenu [The Irtysh Becoming an Ippokrena], Biblioteka uchenaya, 
ekonomicheskaya, nravouchitel'naya, istoricheskaya $i$ uveselitel'naya $v$ pol'zu $i$ udovol'stvie vsiakogo zvaniya chitateley [The Scientific, Economical, Moral, Historical and Entertaining Library for Use and Pleasure of Readers of any Social Status]) activities. Thus, the initial period of the Siberian book printing from Philotheus Leszczynski to the Kornilievs' printing house is highlighted in a new way. The author analyzes Varbeck in the context of Uchilishche lyubvi as well as Sumarokov's translation, editorial and publishing activities during his Siberian exile (1787-1801). She evaluates his contribution to the formation of the national tradition of readers' edification, combining instruction and pleasure, entertainment and education of emotions.

The author shares the hypothesis of V.A. Pavlov, a famous historian of the Ural and Siberian book business, that explains the biographical aspect of the appearance of a Siberian book in Nilov's printing house. It is associated with the personality of Pavel Ivanovich Sumarokov, Sumarokov's cousin-uncle. At the same time, N.P. Dvortsova significantly supplements the biographical aspect with a comparative-typological analysis of Nilov's Tambov printing house and the Kornilievs' Tobolsk printing house. The author investigates the history of the printing houses associated with Catherine II's edicts of 1783 and 1796, the importance of the work of the poets G.R. Derzhavin and P.P. Sumarokov in this story, features of the repertoire of the printing houses, and the significance of periodical and translated publications.

The story of Varbeck publication in Tambov and the nature of the distribution of the first Tobolsk magazines is seen as a manifestation of a new (after Peter the Great's Decree of 1703 to Philotheus Leszczynski, the Metropolitan of Siberia and Tobolsk) approach to the printed book in Siberia in the 18th century. It is understood as an essential part of the all-Russian publishing business, in which books circulated not only from the European part of Russia to Siberia, but also from Siberia to the European part of Russia.

François-Thomas-Marie de Baciulard d'Arnaud is treated as a writer who gained much popularity in Russia in the context of the so-called instructive reading, designed to combine the pleasant and the useful in one novel (story). The author establishes a connection between Sumarokov, the author and translator of Uchilishche lyubvi and Varbek, and the editor of the Uchenaia biblioteka, which published books and journals "for the use and pleasure of readers of all social statuses", and the concept of edifying reading. The research justifies that Sumarokov chose to translate d'Arnaud's Varbeck not only because of the French writer's popularity in Russia, that is, by external reasons, but also by internal reasons related to Sumarokov's experience as a translator of Uchilishche lyubvi.

Analysis of the poetics of Uchilishche lyubvi and Varbek establishes their common system of motives (love, ambition, opposition of the city and nature, feelings and passions, paths, searches, tears, suffering, death, friendship, etc.) and their belongingness to the Russian tradition of enlightenment and education of emotions. 


\section{References}

1. Larkovich, D.V. (2007) Literaturnaya sud'ba Pankratiya Platonovicha Sumarokova (Opyt semanticheskogo analiza) [The literary fate of Pankratii Platonovich Sumarokov (An experience of semantic analysis]. Surgut: Surgut State Pedagogical Univeresity.

2. Volkova, V.N. (ed.) (2000) Ocherki istorii knizhnoy kul'tury Sibiri i Dal'nego Vostoka [Essays on the History of Book Printing Culture in Siberia and Far East]. Vol. 1. Novosibirsk: SB RAS.

3. Leszczynski, P. (1882) Chelobitnaya mitropolita sibirskogo i tobol'skogo Filofeya Leshchinskogo Petru Velikomu i otvet sego gosudarya na nee [The humble petition by Philotheus Leszczynski, the Metropolitan of Siberia and Tobolsk, to Peter the Great, and the Sovereign's answer to it]. In: Sulotskiy, A.I. Svyatitel' Filofey, mitropolit sibirskiy i tobol'skiy, prosvetitel' sibirskikh inorodtsev [St. Philotheus the Metropolitan of Siberia and Tobolsk, Enlightener of Siberian inorodtsy]. Omsk: Tipografiya Akm. obl. pravl.

4. Dmitriev-Mamonov, A.I. (2014) Nachalo pechati v Sibiri [The beginning of printing in Siberia]. In: Mameev, S.N. et al. Russkaya knizhnaya traditsiya v Sibiri: "tobol'skie inkunabuly" [The Russian book tradition in Siberia: "The Tobolsk incunabulas"]. Ekaterinburg: Basko. pp. 23-106.

5. Pavlov, V.A. (2004) Povest' o Pankratii Sumarokove [The novel on Pankratii Sumarokov]. Ural. 6. [Online] Available from: http://magazines.russ.ru/ural/2004. (Accessed: 15th February 2018).

6. Kondakov, I.P. (ed.) (1962) Svodnyy katalog russkoy knigi grazhdanskoy pechati XVIII veka. 1725-1800 [The Joint Catalog of the Russian Civil Book in the 18th century. 1725-1800]. Vol. I. Moscow: Russian State Library.

7. Irtysh, prevrashchayushchiysya v Ipokrenu. (1789) September.

8. Irtysh, prevrashchayushchiysya $v$ Ipokrenu. (1790) January.

9. Konovalova, E.N. (2006) Kniga tobol'skoy gubernii. 1790-1917 [The Book of Tobolsk Province. 1790-1917]. Novosibirsk: SB RAS.

10. Kondakov, I.P. (ed.) (1967) Svodnyy katalog russkoy knigi grazhdanskoy pechati XVIII veka. 1725-1800 [The Joint Catalog of the Russian Civil Book in the 18th century. 1725-1800]. Vol. 5. Moscow: Kniga.

11. Kondakov, I.P. (ed.) (1964) Svodnyy katalog russkoy knigi grazhdanskoy pechati XVIII veka. 1725-1800 [The Joint Catalog of the Russian Civil Book in the 18th century. 1725-1800]. Vol. 2. Moscow: Russian State Library.

12. Levin, Yu.D. (ed.) (1995) Istoriya russkoy perevodnoy khudozhestvennoy literatury. Drevnyalibraryya Rus'. XVIII vek. V 2-kh $t$. [The History of the Russian Translated Fiction Literature. The Ancient Russia. The 18th century]. Vol. I. St. Petersburg: Dmitriy Bulanin.

13. Rak, V.D. (2014) K 200-letiyu redkogo sibirskogo izdaniya iz fondov Biblioteki Akademii nauk ("Uchilishche lyubvi". Tobol'sk, 1791) [To the 200th anniversary of a rare Siberian edition from the funds of the Library of the Russian Academy of Sciences 
(The School of Love, Tobolsk, 1791)]. In: Mameev, S.N. et al. Russkaya knizhnaya traditsiya v Sibiri: "tobol'skie inkunabuly" [The Russian book tradition in Siberia: "The Tobolsk incunabulas"]. Ekaterinburg: Basko. pp. 107-120.

14. Anon. (1791) Uchilishche lyubvi. Anglinskaya povest' [The School of Love. An English Novelette]. Tobolsk: V. Korniliev.

15. Baculard d'Arnaud, T.M. de (1793) Varbek. Anglinskaya povest' [Varbeck. An English Novelette]. Translated from French by P.S. Tambov: A. Nilov.

16. Karamzin, N.M. (1802) O knizhnoy torgovle i lyubvi k chteniyu v Rossii [On book trading and love to read in Russia]. Vestnik Evropy. 9. pp. 57-64.

17. Govorov, A.A. \& Kupriyanova, T.G. (eds) (2001) Istoriya knigi [The History of Books]. Moscow: Svetoton. 